\title{
INTERACTIVE SYSTEM FOR DIGITAL PRESENTATION OF CULTURAL ROUTES AND SPECIALIZED COLLECTIONS Negoslav Sabev ${ }^{1}$, Galina Bogdanova ${ }^{2}$, Pavel Hristov ${ }^{3}$
}

\begin{abstract}
This article discusses issues related to the design of interactive applications which aim to demonstrate human interaction with computer systems in areas including creative industries, cultural tourism and education. Investigations related to the digitization of special collections of cultural property in the Veliko Turnovo region are going to be presented. Various processes are described for the documentation and digitization of specialized archives. Ways and methods are discussed for generation and digital presentation of thematic collections and routes of cultural history in the Veliko Turnovo region. A specific module with interactive digital resource maps is created which are stored in North+ Digital Center repositories. It presents a model for creating an interactive system in need for visually impaired people. This model also ensures the usability of the interactive system for people with disabilities. Digitized objects in archives, thematic cultural routes and collections can be used for educational purposes in studying the cultural heritage of the North+ region.
\end{abstract}

UDC Classification: 004.4, 304, DOI: 10.12955/cbup.v7.1490

Keywords: Cultural routes, collections, digitization, interactive system, accessibility, disabilities

\section{Introduction}

Digitization of cultural values and special collections has become a widespread topic in recent years. Digital presentation of collections of cultural values in the Veliko Turnovo region and documenting specialized archives for "Culture and Tourism" department of the Veliko Turnovo municipality, are the main described topics of this paper. An important issue is bringing together similar institutions in the preservation and digitization of cultural and documentary heritage in regard to a modern center for digitization in interdisciplinary North+ projects. It allows the unification process for digitalization and the creation of full-text databases. As a result, a digitized center can provide wide access to cultural heritage in North Central region institutions and preserve original cultural sites long term for future generations.

Another important aspect is the digitization and promotion of book cultural heritage. Digital technologies, the creation and indexing of cultural heritage resources, and their use on public websites were explored. A model of an accessible interactive system for people with disabilities is also presented.

\section{Organization and digitization of specialized archive collections}

This paper relates to "Culture and Tourism" department of the Veliko Turnovo municipality which stores the "Cultural and historical heritage" archive fund - local specialized scientific and documentary archive collection of cultural heritage. The main objective is to study, save and annotate this documentary heritage as a possibility for public access.

Sites for digitizing records of technical documents, maps, plans on paper, normative documents and lists, scientific research, surveys and old photo documentation of cultural heritage are described. Specialized research and analysis of existing methods and technologies for digitization and content archive records of cultural heritage requires certain specifics on some technical data necessary for the identification of objects and the linking of archive units. Available collections of specialized archives and important data, name of cultural value, location, address, type and category are set under Cultural Heritage Law and GPS data.

Annotation and indexing of digitized objects is entered as cultural property data under the Cultural Heritage Law - archaeological, historical buildings, other structures and historical places, architectural buildings, art works of fine and applied arts, parts of areas and settlements, park and garden art, ethnographic and material evidence of life, crafts, skills, customs, cultural sites as a collection of a historical route of traditional way with objects included for cultural heritage and landscapes. There is also important information to be entered of a digitalized object such as global data inscribed in the World Heritage List, "National importance" - archaeological reserves, and other cultural objects of exceptional

\footnotetext{
${ }^{1}$ Institute of Mathematics and Informatics, Bulgarian Academy of Sciences, Veliko Tarnovo, Bulgaria, negoslavsabev@gmail.com

${ }^{2}$ Institute of Mathematics and Informatics, Bulgarian Academy of Sciences, Sofia, Bulgaria,

g.bogdanova@gmail.com

${ }^{3}$ Faculty of Mathematics and Informatics, St. Cyril and St. Methodius University, Veliko Tarnovo, Bulgaria, pavel.hristov@outlook.com
} 
value to the culture and history of the country, "Local significance" - related culture and history of settlements, municipalities or districts, "Ensemble importance" - supporting spatial characteristics and architectural typology group value.

Technical data about objects should be presented - conceptual and technical projects in parts of architecture, civil engineering, electricity, water supplies, landscaping, author data, date or year documentation - photographs, records, programs. The archive for cultural heritage of group and individual cultural values of the Veliko Turnovo Municipality project "Digital cultural treasure North+" is named the "Cultural heritage archive of Veliko Turnovo municipality".

The specialized archive consists of three collections:

"Archaeological states" collection - "Tsarevets" archaeological state with objects - Palace, Patriarchy, churches, monasteries, buildings, walls; "Trapezitza" archaeological state with objects - walls, monasteries, churches and buildings; "Momina fortress" archaeological state with objects - walls, monasteries, churches and buildings; "Nicopolis ad Istrum" archaeological state with objects - remains of streets, walls, buildings.

"Historical Settlement of Veliko Turnovo" collection - "Old public buildings - real cultural values" with objects - buildings of Deboya, prison, Konak building; "Old religious buildings - real cultural values" with objects - churches, metropolitan monasteries and mosques; "Old buildings from the Renaissance cultural century" with objects - buildings; "Buildings after the Ottoman rule cultural values" with objects - buildings; "Old industrial buildings cultural property" with objects - shops, bakeries, mills, factories; "Architectural and Urban Heritage" with objects - drawings, documents, old photographs.

"Monasteries" collection with objects - Preobrazhenski Monastery, Kilifarevo Monastery, "St. Nikolay" Monastery, Prisovski Monastery, "St. Ilia" Monastery - Plakovo, "St. Troitsa" Monastery, "St. Maria" Monastery - Arbanassi, "St. Nikolay" Monastery - Arbanassi.

The digitization process can further proceed with the "Monumental Monuments" collection, "Bridges and cultural value status sites" collection, "Historical Settlement Arbanassi" collection, "3D documentation of objects - NCC of national importance" collection and photos.

The process is done by using modern digitization tools and technology according to a specific plan. Panels and collections are stored in tree-organized digital repositories, archives and collections in the "Digital Cultural Heritage North +" system.

Activities for digitization of special collections concerning real cultural values for archives of "Culture and Tourism" directorate of the Veliko Turnovo municipality include scanning, indexing of digital files and digital archive records. The overall process is starting with priority documentation for most significant sites according to importance, category and significance as community, religious buildings, monasteries and residential buildings. It can also include the type of archive documentation - technical data with architecture projects, urban plans, detailed plans, brochures, newspapers, regulations, protocols, old photographs, selected objects field, processing and annotation of digitized objects stored in special archives, repositories for digital raw materials, the introduction of digital information for North+ workstations in a web programming environment.

\section{Interactive presentation of thematic cultural routes and collections in a virtual map platform}

Modern interactive technologies are a new stimulus for the development of the cognitive system in learners of all ages. Culture maps and geographic information systems are explored by Freeman (1983), Cosgrove (1999), Anheier and Yudhishthir (2007), Maliene at al. (2011) and Meyer (2014). Usability, user experience and interface are analyzed and described by Axtell and Dixon (2002), Petrie and Bevan (2009), Atanasova and Malinova (2017) and Petrie at al. (2018).

Specific cultural routes are embedded in a web platform. Mobile functionality has also been developed. An interactive map has been developed as an accessible platform for cultural sites, activities and practices on the web. REST API is implemented for retrieving information through programming languages such as JavaScript and Python. The process of data gathering through API is described, which locally caches results and visualizes the necessary information.

The platform has implemented responsive design, which helps the interactive map to work on all popular mobile and desktop devices running a modern browser. Different icons were developed for various types of objects and events. Filters exist for each category of objects. Full CMS functionality is created for the 
description of objects, which gives the ability to add photos, files, videos, and additional galleries. There is also support for a set of attributes like name - multilingual content, type and category of object, text description, geographical location, main picture, set of additional media - photos, videos, files.

An interactive map is created which provides a solid base for cultural infrastructure and to visualize in a modern way the presentation of cultural identity, objects and routes (Figure 1).

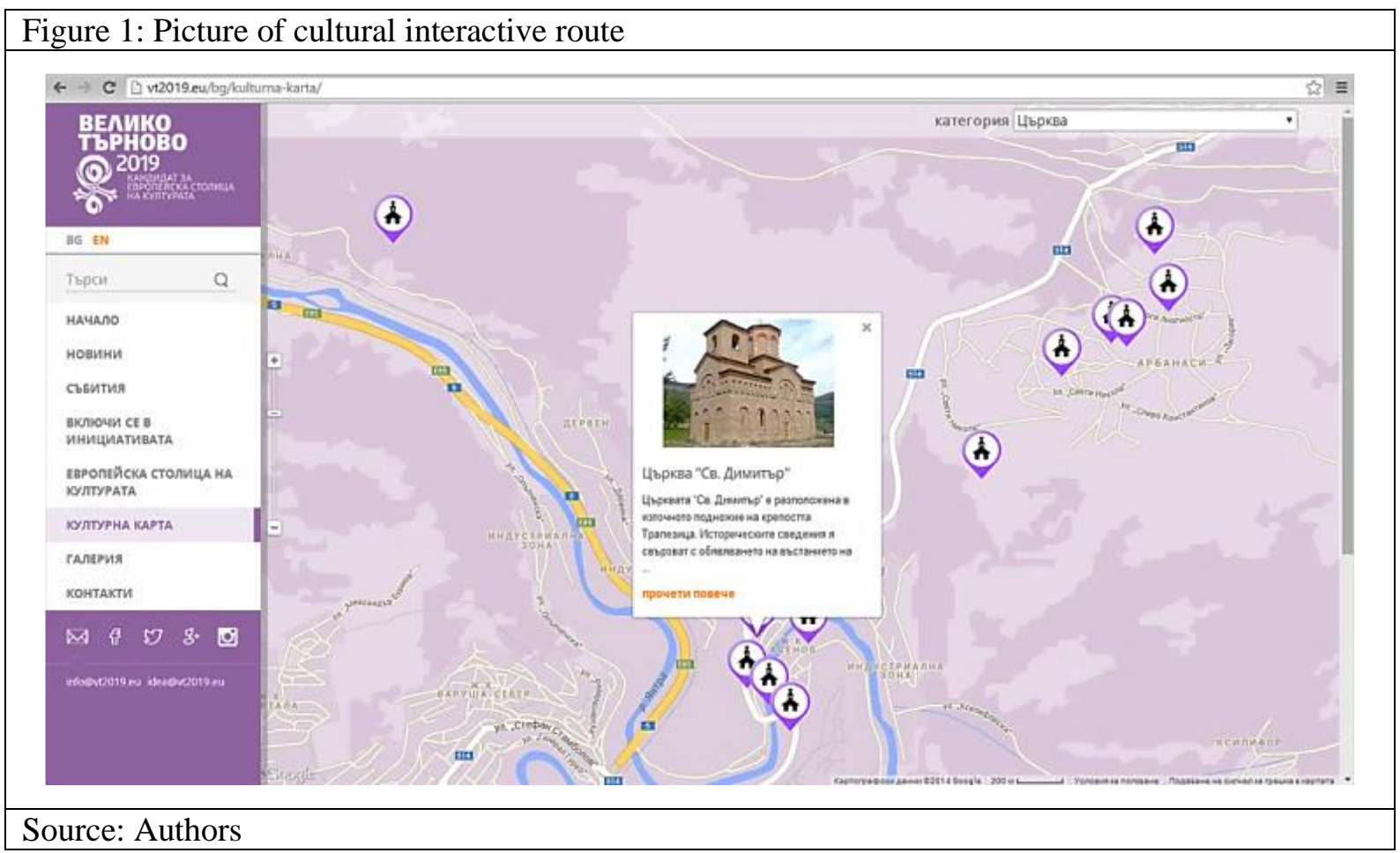

All digitized objects stored in different repositories, selected thematic collections and routes from the North+ software environment can also be generated. The software allows the generation of thematic collections from all repositories on with selected criteria and/or themes. For example, in the thematic collection "Master Kolyo Ficheto" are included all collections in North+ region related to Master Kolyo Ficheto. Thematic cultural routes are presented through the interactive map like the "Religious Sites in Veliko Turnovo - Arbanassi" route.

Digitized objects in archives, thematic cultural routes and collections can be used for educational purposes in studying the cultural heritage of the North+ region. Suggestions have been explored due to more opportunities for the optimized use of digital resources in applications for people with disabilities and visually impaired people.

\section{Web accessibility standards and model of an accessible interactive system for people with disabilities}

People with disabilities want to be able to access various applications on the web. The study of software systems and universality principle implies that computer information systems are oriented to a wide range of users regardless of their age or disability. Web accessibility of software applications are investigated by Sabev et al. (2018). In recent years, the focus has been on public websites, covering functionality for various web access. The problems of accessibility of public sites are studied by Bogdanova et al. (2016), Bogdanova and Sabev (2017) and Sabev and Bogdanova (2018). Usability, user experience, interface and website accessibility are explored and analyzed in detail by Ferre et al. (2001), Stewart et al. (2005), and Power and Petrie (2019). The accessibility of websites and web applications has been studied by various authors in many countries. The accessibility of websites in Turkey was investigated by Kurt (2011) and Akgül et al. (2016). Kurt re-reviewed the same web sites after five years (2016). Website accessibility in Finland has been studied in the work of Karhu et al (2012). 
Web Content Accessibility Guidelines ${ }^{4}$ (WCAG) are being developed in order to meet recommendations for the needs of people with disabilities. The first accessibility standard ${ }^{5}$ for people with disabilities (WCAG 1.0) was created in 1999 by the W3C 6 . WCAG $2.0^{7}$ was launched in 2010 . The latest version of WCAG 2.1 was released in 2018. For the accessible interactive system, WCAG 2.1 standard should be met. Adhering to website accessibility standards ensures that software application is used by a wider audience.

In order for an interactive system to be accessible for people with disabilities, it should be designed so that it can work regardless of physical issues. The accessible interactive system for people with disabilities is used with accessibility technologies which make it easy for system access with screen magnifiers, screen readers, touchscreen, braille printers and keyboards. Accessibility implies that web and interactive systems take into account the specificities of people with disabilities. For blind people, there should be built-in alternative text for images in the system.

The authors explore the necessary functionalities in order to facilitate access to the interactive system by people with visual deficits. Testing accessibility of the interactive system and recommendations for adding necessary accessibility features for blind people is done by one of the authors who has the required expertise and 100\% visual impairment. The system can also be useful in training people with disabilities as additional informal learning (Tramonti et al. 2017). The development of the system in the direction of accessibility contributes to more opportunities for acquiring knowledge and training in the cultural heritage of people with disabilities.

\section{Conclusion}

Preservation and presentation of information on cultural values of the North+ region with modern tools and technology is an important factor for gaining knowledge and getting acquainted with the cultural history of the region. The article discusses activities of the interdisciplinary project North+ related to the digitization and documentation of the specialized archive of the "Culture and Tourism" department of the Veliko Turnovo municipality as well as the digitization of real objects of cultural archives. The module can be a basis for further in-depth studies on cultural infrastructure for thematic and technical studies of places for culture in various ways. Digitized objects in archives and presented thematic cultural routes and collections can be used for educational purposes in studying the cultural heritage of the North+ region. The development of the system in the direction of accessibility contributes to opportunities for acquiring knowledge and training in cultural heritage by people with disabilities. Through the implementation of the specific project activities an active policy is created for the preservation of Bulgarian cultural heritage.

\section{Acknowledgements}

The work of the first two authors was supported in part by Grant 1909C/2019 of the Technical University of Gabrovo.

\section{References}

Akgül, Y. \& Vatansever, K. (2016). Web Accessibility Evaluation of Government Websites for People with Disabilities in Turkey. Journal of Advanced Management Science. https://doi.org/10.12720/joams.4.3.201-210

Anheier H.K, Raj Isar Yudhishthir (2007) Cultures and Globalization: Conflicts and Tensions (The Cultures and Globalization Series) (v. 1). SAGE Publications, 243-245, ISBN-13: 978-1412934725 ISBN-10: 1412934729

Atanasova, M., Malinova, A. (2017). Transforming Concur Task Trees Model into an Abstract User Interface. CBU International Conference on Innovations in Science and Education. March 22-24, 2017, Prague, Czech Republic, 1036-1041. https://doi.org/10.12955/cbup.v5.1067

Axtell, R., Dixon, J.M. (2002). Voyager 2000: a review of accessibility for persons with visual disabilities. Library Hi Tech 20(2), 141-171 https://doi.org/10.1108/07378830210432507

Bogdanova, G., Sabev, N., Tomov, J. (2016). Web Accessibility Guide, Horizons Fondation, Sofia, Retrieved from http://webaccess.horizonti.bg/narychnik

\footnotetext{
${ }^{4}$ Web Content Accessibility Guidelines (WCAG) Overview, Retrieved from https://www.w3.org/WAI/intro/wcag

${ }^{5}$ Web Content Accessibility Guidelines 1.0, Retrieved from https://www.w3.org/TR/WAI-WEBCONTENT/

${ }^{6}$ W3C (1999). Web content accessibility guidelines 1.0. W3C Recommendation. Cambridge: W3C. Retrieved from https://www.w3.org/TR/WAI-WEBCONTENT/

${ }^{7}$ Web Content Accessibility Guidelines (WCAG) 2.0, Retrieved from https://www.w3.org/TR/WCAG20/
} 
Bogdanova, G., Sabev, N. (2017). The second principle of operability in the standart for web accessibility WCAG 2.0., XVNational Conference with international participation "Libraries - reading-communications" - Digital conversion of literary and cultural heritage, 302-314

Cosgrove, D. E. (1999). Mappings. Reaktion Books (April 15, 1999, 320 pages) ISBN 1-86189-021-4 https://doi.org/10.1177/03058298010300030905

Ferre, X., Juristo, N., Windl, H., Constantine, L., (2001). Usability Basics for Software Developers. IEEE SOFTWARE, $22-$ 29. https://doi.org/10.1109/52.903160

Freeman, H. (1983). Map data processing and the annotation problem. Scandinavian Conference on Image Analysis. Chartwell-Bratt Ltd. Copenhagen

Karhu, M., Hilera, J. R., Fernández L., Ríos, R. (2012). Accessibility and readability of university websites in Finland, https://doi.org/info:doi/10.17411/jacces.v2i2.70

Kurt, S. (2011). The accessibility of university websites: The case of Turkish universities. Universal Access in the Information Society, 10(1), 101-110 https://doi.org/10.1007/s10209-010-0190-z

Kurt, S. (2016). Accessibility of Turkish University Web sites. Univ. Access Inf. Soc https://doi.org/10.1007/s10209-016-0468-x

Maliene, V., Grigonis, V., Palevičius, V., Griffiths, S. (2011). Geographic information system: Old principles with new capabilities. Urban Design International 16 (1), 1-6. https://doi.org/10.1057/udi.2010.25

Meyer, E. (2014). The Culture Map: Breaking Through the Invisible Boundaries of Global Business. PublicAffairs (Hardcover: 288 pages, 1 edition May 27, 2014) ISBN-10: 9781610392501 ISBN-13: 978-1610392501 https://doi.org/10.15733/jast.2018..76.243

Power, C., Petrie, H. (2019). Working With Participants. In: Yesilada Y., Harper S. (eds) Web Accessibility. HumanComputer Interaction Series. Springer, London https://doi.org/10.1007/978-1-4471-7440-0_9

Petrie, H., Bevan, N. (2009), The Evaluation of Accessibility, Usability, and User Experience, The Universal Access Handbook, 1, 1-16, C.Stepanidis (ed), CRC Press, https://doi.org/10.1201/9781420064995-c20

Petrie, H., Weber, G., Jadhav, C., Darzentas, J.S. (2018). Issues of Culture in Designing for Accessibility. In: Clemmensen T., Rajamanickam V., Dannenmann P., Petrie H., Winckler M. (eds) Global Thoughts, Local Designs. INTERACT 2017. Lecture Notes in Computer Science, vol 10774. Springer, Cham https://doi.org/10.1007/978-3-319-92081-8_6

Sabev, N., Bogdanova, G. (2018). Digital and Physical Accessibility of Tourist Places in Bulgaria Pages. Cultural and Historical Heritage: Preservation, Presentation, Digitalization. 5, 38-58. Institute of Mathematics and Informatics at the Bulgarian Academy of Sciences, Sofia \& RPL"P. R. Slaveykov" Veliko Tarnovo, https://doi.org/10.21125/iceri.2018.1810

Sabev, N., Bogdanova, G., Georgieva-Tsaneva, G. (2018). Creating a Software System with Functionality to Help Make it Accessible for People with a Visual Deficit. CBU International Conference on Innovations in Science and Education. Central Bohemia University. Prague, Czech Republic, CBU Research Institute, 6, 734-738, https://doi.org/10.12955/cbup.v6.1241 Stewart, R., Narendra, V., Schmetzke, A. (2005). Accessibility and usability of online library databases. Library Hi Tech 23(2), 265-286 https://doi.org/10.1108/07378830510605205

Tramonti, M., Paneva-Marinova, D., Pavlov, R. (2017). Math and Art Convergence for Education. CBU International Conference on Innovations in Science and Education. March 22-24, Prague, Czech Republic, 5, 851-854.

https://doi.org/10.12955/cbup.v5.1037 